Meta

Journal des tradlucteurs

Translators' Journal

\title{
Pirates de terre ferme
}

\section{Robert Dubuc}

Volume 21, numéro 2, juin 1976

URI : https://id.erudit.org/iderudit/002624ar

DOI : https://doi.org/10.7202/002624ar

Aller au sommaire du numéro

Éditeur(s)

Les Presses de l'Université de Montréal

ISSN

0026-0452 (imprimé)

1492-1421 (numérique)

Découvrir la revue

Citer cet article

Dubuc, R. (1976). Pirates de terre ferme. Meta, 21(2), 141-142.

https://doi.org/10.7202/002624ar

Ce document est protégé par la loi sur le droit d'auteur. L’utilisation des services d'Érudit (y compris la reproduction) est assujettie à sa politique d'utilisation que vous pouvez consulter en ligne.

https://apropos.erudit.org/fr/usagers/politique-dutilisation/
Cet article est diffusé et préservé par Érudit.

Érudit est un consortium interuniversitaire sans but lucratif composé de l’Université de Montréal, l'Université Laval et l'Université du Québec à Montréal. Il a pour mission la promotion et la valorisation de la recherche. https://www.erudit.org/fr/ 


\section{DROBLÈMES ET SOLUTIONS}

\section{PIRATES DE TERRE FERME *}

Par un cheminement difficile à expliquer autrement que par des hypothèses, le mot pirate en anglais est devenu une sorte de synonyme caractérisé du mot illégal dans des expressions que la presse écrite et parlée des dix dernières années a largement répandues : pirate station et pirate recording.

La première de ces deux expressions désigne « an independent station broadcasting without government license ${ }^{1}$ ». Le mot pirate s'applique donc à toute station de diffusion de radio ou de télévision à qui l'autorité compétente n'a pas accordé un permis d'exploitation. Il s'agit d'une infraction à la loi dans le domaine de la diffusion par ondes hertziennes.

Ce sens n'est pas sans analogie avec celui de la deuxième expression, pirate recording, où le mot pirate vise cette fois une infraction à la loi de la protection de la propriété artistique : «A recording made in infringement of copyright ${ }^{2}$. 》

Nous voici avec deux pirates bien en vie auxquels il faut trouver des équivalents en français.

Le mot pirate en français se présente d'emblée à l'esprit : sa réputation de mauvais garçon pouvant bien le servir dans l'illégalité impliquée par le terme anglais.

Si on consulte les dictionnaires français courants, on s'aperçoit que le mot y est donné avec un sens très voisin du mot anglais dans l'expression pirate station. «Emetteur pirate : poste d'émission non autorisé, fonctionnant sur une longueur d'ondes qui ne lui a pas été attribuée ${ }^{3}$.

* Les recherches à la base de cet article ont été faites avec le concours des étudiants du cours TRA 6020, de l'Ecole de traduction de l'Université de Montréal.

1. Encyclopaedia Britannica (Micropaedia), Chicago, William Benton Publisher, 1970, vol. 7, p. 1.

2. D'après le Webster's Third New International Dictionary, Springfield (Mass.), Merriam and Company, 1971, au mot pirate.

3. Grand Larousse encyclopédique, Paris, Larousse, 1968, vol. 8, p. 512. 
Quant au second sens, les dictionnaires usuels n'en font pas état. Gilbert donne un exemple d'utilisation emprunté au domaine de l'édition. «On s'attend que Formose devienne la base d'une édition-pirate/qui fasse une fructueuse concurrence à l'édition édulcorée mise en vente aux États-Unis » (le Monde 24-1266) ${ }^{4}$.

Il est intéressant de noter au passage que Gilbert ne considère pas le mot pirate dans ces emplois comme un adjectif, mais plutôt comme un élément d'un mot composé, d'où l'usage du trait d'union dans les expressions où figure ce mot. Il contredit en cela le Grand Larousse encyclopédique.

Il faut chercher dans des publications plus récentes encore pour trouver un exemple d'utilisation de pirate, directement lié aux techniques d'enregistrement. «Le disque pirate a plus fait pour la musique en général et pour l'opéra en particulier que bien des maisons chevronnées. Et puis s'il n'y avait pas des micros sauvages pour capter le moment de grâce où un artiste atteint au sommet de lui-même, serait-on sûr de jamais lui avoir rendu justice ${ }^{5} . »$ On voit bien, d'après cet exemple, qu'il s'agit d'un enregistrement fait clandestinement, sans autorisation, en infraction du droit de propriété artistique.

Avec ce dernier sens de pirate, nous sommes en pleine néologie sémantique. Il s'agit d'une acception récente, probablement prise à l'anglais, mais qui fait image et qui devient à la mode.

Il est douteux qu'à un niveau plus élevé que celui de la langue des journaux et de l'actualité, la langue juridique se satisfasse de ce néologisme. On sait par expérience que c'est un domaine qui s'accommode mal de nouveautés. Dans l'état actuel de la langue juridique on voit assez mal un contrat de cession de droits employer l'expression enregistrement-pirate. Il faut donc se reporter à des mots plus « classiques » comme illégal et illicite; le premier s'appliquant lorsqu'il y a infraction à une loi, le second à une transgression d'un certain ordre moral, soutenu ou non par des textes de loi. $\grave{A}$ un niveau moins officiel, le mot clandestin conviendrait également très bien. Pourrait-on parler de contrefaçon et d'enregistrement contrefait? En dépit d'une certaine imprécision des textes de loi à cet effet, il semble bien que l'adjectif contrefait se dise surtout d'une imitation d'une œuvre originale et d'une reproduction non pas intégrale mais illicite.

En résumé, disons que pour rendre l'expression pirate station, l'expression station pirate semble entrée dans l'usage, de même que les expressions voisines émetteur pirate, poste pirate, avec ou sans trait d'union. Quant à pirate recording, l'expression enregistrement pirate rend encore un son familier qui lui ferait préférer, au moins dans les textes officiels ou soutenus, les expressions enregistrement illégal ou illicite ou enregistrement clandestin.

Robert Dubuc

4. Pierre Gilbert, Dictionnaire des mots nouveaux, Paris, Hachette-Tchou, 1971, p. 387.

5. Le Nouvel Observateur, Paris, Le Nouvel Observateur du monde, 1975, $\mathrm{n}^{\circ}$ 563, p. 51

6. Rock and Folk (revue française de musique pop), dans son numéro de juin 1975, appelle les disques pirates «disques blancs 》 à cause des pochettes immaculées des premiers enregistrements clandestins. 